\title{
nature
}

\section{Cells, FAQs and a new monthly journal}

Cell biology is flourishing, in the liveliness of its community and in the breadth and connectivity of the science. Hence today's launch of Nature Cell Biology, complementing Nature's continuing enthusiasm for the subject.

T he grand quest of cell biologists is to understand how cells function and communicate with each other, working together to form tissues, organs and the great variety of life. Fundamental aspects such as cell division, protein sorting, programmed cell death (apoptosis) and the organization of the cell nucleus are less and less studied in isolation. The roles of signalling molecules and complexes, likewise, are increasingly understood in the context of crosstalking networks rather than individual pathways. The pace of discovery is rapid, the need for different areas of expertise to be brought together ever greater: cell biology is both competitive and integrative. That provides fertile ground for a monthly Nature journal intended to serve all those working on cell biological problems.

Whenever a new Nature journal is announced, Nature's editorial staff are frequently asked several questions. For example, will the community welcome it, given existing specialist publications? Our publishers' positive answer to this is based on two considerations. First, the signs are already good for Nature Cell Biology. Responses by researchers from questionnaires and discussion groups in several countries were positive, advance subscriptions are at a healthy level and, according to Annette Thomas, Nature Cell Biology's editor, there is a stack of high-quality papers on its way. Second, the journal faces similar publishing challenges to other monthly Nature journals when they were launched; they have all prospered, occupying leading positions in their respective disciplines.

Another FAQ: does this mean that Nature is abandoning the discipline? The answer is, as always, emphatically no - Nature's policies are unchanged. Our editors will continue to strive to publish the most complete studies providing major conceptual breakthroughs, not least in cell biology. The description of the enzyme (DNase) responsible for the breakdown of DNA during apoptosis (Nature 391, 43-50;
1998 ) is one celebrated example. A more recent set of papers exemplifies the virtues of multidisciplinary scope: four papers in our 8 April issue (Nature 398, 513-529; 1999) tell the tale of how a major signalling pathway (the Notch pathway) known to regulate cell-fate decisions during development depends on the actions of presenilin1 , a protein involved in processing the amyloid precursor protein implicated in Alzheimer's disease. And this week's issue sees an important step in the understanding of processes in the nucleus regulating the cell cycle (pages 818-823; News and Views, pages 757-758).

From today there are six monthly Nature journals (see http://www.nature.com/author/natureguide.html). Nature Cell Biology is no different from the others in seeking to publish landmark papers within its discipline, as well as authoritative comment. For a full discussion of its scope and ambitions, see the editorial in its first issue, available at http://cellbio.nature.com. Moreover, the journal has the same relationship to Nature itself. The editorial teams act fully independently: Nature Cell Biology's editor is the final arbiter of what it should publish, and there is no discussion between the journals before either takes a decision on a paper. But if Nature editors decide to reject a paper, for example on the grounds of insufficient breadth of impact, but feel that it would still be of exceptional interest to the cell biology community, they will suggest submission to Nature Cell Biology and offer to pass on all referees' comments to save time. This approach has proved successful with the other monthlies and, for authors, ensures that papers are judged on consistently independent criteria.

We look forward to serving the cell biology community with both journals, as it enjoys an era of unprecedented growth and diversity.

Philip Campbell — Editor, Nature

\section{Smallpox preservation advisable}

\section{Previous agreements notwithstanding, it makes sense not to destroy a key protective resource.}

The decision by the Clinton administration not to proceed with the planned destruction of its store of smallpox (page 741) is well taken. A report last month by the US Institute of Medicine did not pronounce on whether the store should be destroyed, as the United States agreed to do in 1996 under a World Health Organization plan. But it lays out a persuasive case for the potential public-health benefits of retaining the live virus, which is frozen in a maximum-containment laboratory at the Centers for Disease Control and Prevention (CDC) in Atlanta, Georgia, accessible to only six highly trained scientists, and at a Russian government laboratory in Siberia.

The lack of effective antiviral medications would not be of so much concern were it not for the growing vulnerability of a population that has not been routinely vaccinated now for a generation. Were the disease to re-emerge - whether accidentally or at the hands of terrorists or a rogue nation - the results could be catastrophic. Careful science under the auspices of the $\mathrm{CDC}$, testing candidate medications against the virus in cell culture and, later, in monkey models, may offer the only serious weapon to respond to an epidemic, if not to prevent it.

In addition, a new, large population of the immunosuppressed now exists, thanks to organ transplantation, cancer chemotherapy and AIDS. These people deserve the potential benefit of a novel vaccine if the disease again became endemic. But development of such a vaccine would require the live virus.

Rightly, public-health advocates bemoan the prospect of any measure that increases the risk of a re-emergence of this scourge. But, given the impossibility of knowing who now possesses the virus, and from where it might appear, it is better to have a number of arrows in the quiver than to destroy the stock and cross our collective fingers. 